\title{
The role of climatic variability on the short-term fluctuations of octopus captures at the Canary Islands
}

\author{
A.M. Caballero-Alfonso ${ }^{\mathrm{a}, 1}, \mathrm{U}$ Ganzedo $^{\mathrm{b}}$, A. Trujillo-Santana ${ }^{\mathrm{a}, 1}$, J. Polanco $^{\mathrm{b}}$, \\ A. Santana del Pino ${ }^{\mathrm{a}, 1}$, G. Ibarra-Berastegi ${ }^{\mathrm{c}}$, J.J. Castro-Hernández ${ }^{\mathrm{a}, *}$ \\ a Faculty of Marine Sciences, University of Las Palmas de Gran Canaria, Edf. Ciencias Básicas, Campus Universitario de Tafira, 35017 Las Palmas de Gran Canaria, Spain \\ ${ }^{b}$ Department of ApPtied Physics II, Fac. of Science and Technôfyy, University of the Basque Country, Barrio Sarriena s/n, 48940 Leioa, Spain

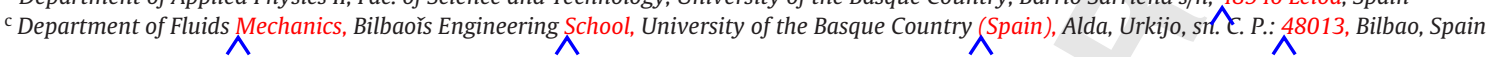

\section{A R T I C L E I N F O}

\section{Article history:}

Received 15 June 2009

Received in revised form

14 December 2009

Accepted 15 December 2009

\section{Keywords:}

Octopus vulgaris

Canary Islands

Climatic variability

North Atlantic Oscillation (NAO)

\begin{abstract}
A B S T R A C T
The effect of temperature on the common octopus life cycle has been well studied. However, how other climatic patterns affect them is poorly understood. The present work emphasises the importance of the temperature on common octopus catches by the small-scale trap fishery off the Canary Islands, and also highlights the effect of the North Atlantic Oscillation (NAO) pattern. As well as an inverse and significant correlation between octopus abundance (measured $\widehat{\widehat{A}}$ CPUE) and Sea Surface Temperature (SST), a direct relationship between abundance and NAO, off the Canary Archipelago, is reported. Using a linear model $(\mathrm{lm})$ with a stepwise procedure, SST is found to be the most important and significant variabß in autumn, accounting for $34.21 \%$. Meanwhile, the NAO became more important in spring with $28.64 \%$ and a $31.13 \%$ of the explained variance in autumn.
\end{abstract}

(c) 2009 Elsevier B.V. All rights reserved.

\section{Introduction}

Due to the short life cycle and fast growth of many cephalopod species, the standing stock (or biomass) of a given area may not necessarily be a good indicator of its exploitation status. The short overlap in successive cohorts creates a lack of "buffering" for natural fluctuations in abundance that is driven by oceanographic or climatic factors. For these reasons, in these species it is more feasible to differentiate the climatic effect from the influence of fishing, because their response to environmental fluctuations should be faster (Hernández-García et al., 2002; Pierce et al., 2008).

Common octopus (Octopus vulgaris) is one of the most important target species for the industrial fleets which operate in the Northwest Africa upwelling system (Balguerías et al., 2000; Faure et al., 2000). It is also the case for the small-scale trap fishery off the Canary Islands, since it represents $2-32 \%$ of the total catch landed by the local fleet (Hernández-García et al., 1998, 2002; authors data unpublished).

This cephalopod fluctuates drastically on large spatial and temporal scales, due to changes in biological and physical variables that have been proposed as determining factors in its survival (Faure et al., 2000). Solari (2008) pointed out that the capture oscillations

\footnotetext{
* Corresponding author. Tel.: +34 928454549; fax: +34 928452922. E-mail address: jcastro@pesca.gi.ulpgc.es (J.J. Castro-Hernández). $\wedge^{1}$ Tel.: +34 928454549; fax: +34 928452922.
}

during the last 50 years of 0 . vulgaris in the Northwest African upwelling system are intimately connected to the North Atlantic Oscillation (NAO) index variation. However, although it may be one of the climate variables which could cause fluctuations in cephalopod abundance (Sims et al., 2001), its effect is complex even if it shows a positive and linear relationship with captures (Hsieh and Ohman, 2006). Locally changes due to atmospheric forcing can be rapid, but to see them on a large-scale, several years are needed (Bjerknes, 1964; Visbeck et al., 2003).

Capture oscillation could be a consequence of a combination of recent past climate variability and the effect of high fishing pressure on paralarvae and yearly recruitment. Moreover, it is necessary to bear in mind that this species has a very short life cycle, around 1 year, and the duration of its embryonic development and the planktonic stage of its paralarvae are highly temperature dependent (Mangold, 1983; Hernández-López et al., 2001). Also the seasonal temperature oscillations greatly affect its benthic settlement (Katsanevakis and Verriopoulos, 2006b). Therefore, delay between recruitment failure and captures should be short.

Off the Canary Archipelago, as in the neighbouring African grounds, copulation and spawning of octopus take place throughout the whole year (Nigmatullin and Ostapenko, 1977; Hatanaka, 1979; Hernández-García et al., 2002). However, two periods of maximum reproductive activity can be identified for this specie; one from January to July with the peak in April, and the second one from October to November, with slight local variations (Guerra, 1992; Faure et al., 2000; Hernández-García et al., 2002; 


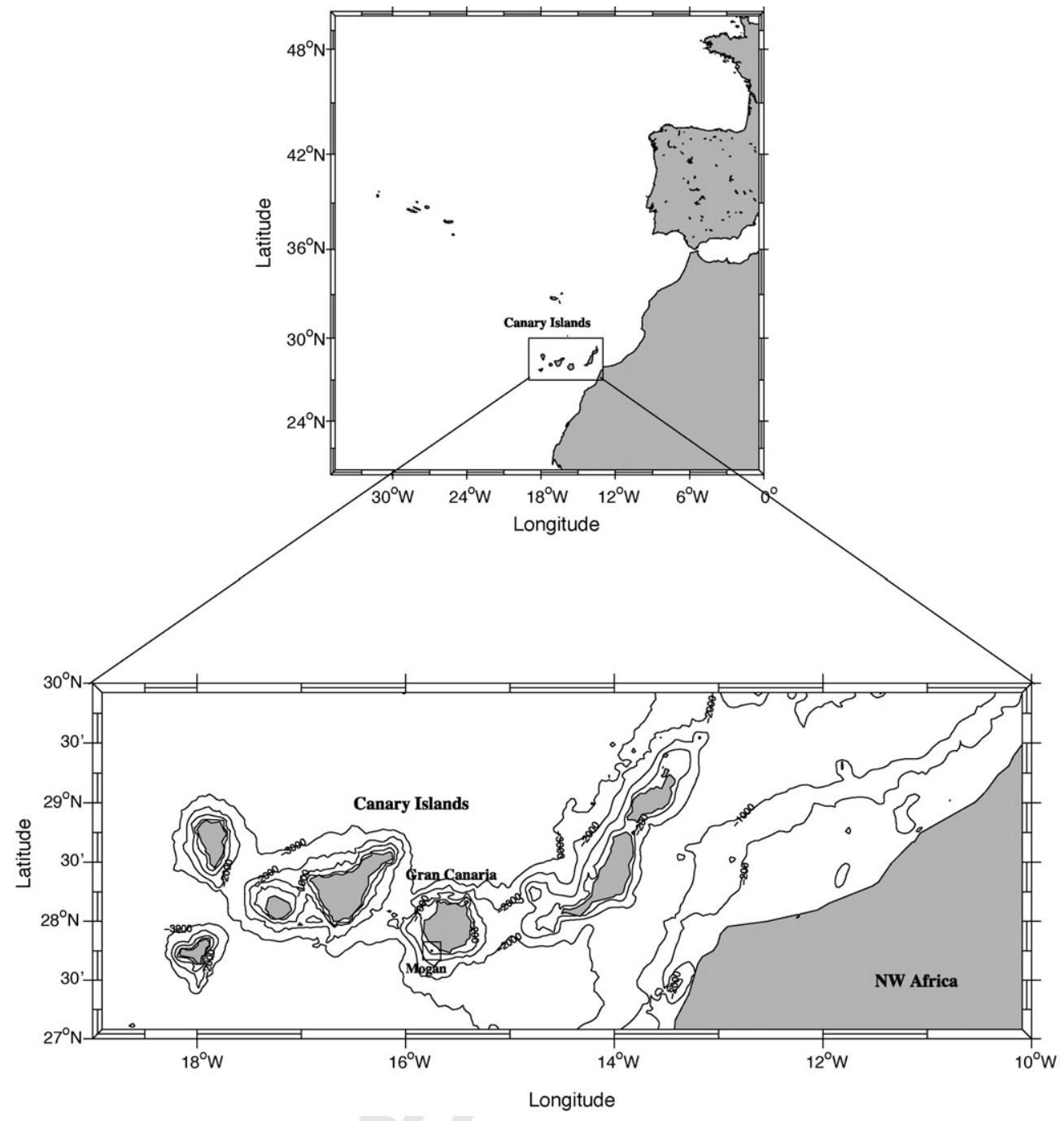

Fig. 1. Canary Archipelago map and catch location (SW Gran Canaria).

Katsanevakis and Verriopoulos, 2006a). In the northwest of Spain, the octopus reproductive cycle seems to be linked to the upwelling seasonality (Otero et al., 2008), while off Mauritania the relationship between recruitment and upwelling variability is seasonally dependent but not always related to the upwelling state; this is probably a reason for changes in the depth of the spawning grounds in spring and autumn (Faure et al., 2000). In accordance with this, Hernández-García et al. (2002) also pointed out that the intensity of the two annual maximum catches of octopus off the Canaries, related to the reproductive concentrations of individuals, are late winter-early spring sea water temperature dependent. In any case, this indicates the presence of, at least, two annual cohorts; generating well separated spawning-catching peaks. Of course, the relative importance of each seasonal peak is dependent on environmental conditions, although Katsanevakis and Verriopoulos (2006a) point out that the second settlement is much more environmentally dependent than the first one.

Studies that evaluate the effects of environmental variability on the cephalopods, and particularly octopus, are scarce and sometimes contradictory. However, the influence of temperature on octopus abundance is always highlighted due to its importance in the first stages of its development (Mangold, 1983; Villanueva, 1995). In line with this, Sobrino et al. (2002) found that the maximum octopus abundance coincided with the minimum Sea Surface Temperature (SST) registered at the studied domain (Gûlf of Cádiz).
In contrast, Balguerías et al. (2002) and Moreno et al. (2002) reported for the Saharan Bank and the Portuguese coast, respectively, that maximal captures coincided with the highest SST in those domains.

There is an increasing interest to understand how climate variability might affect different marine populations, mostly with the objective of predicting its possible evolution and to manage according to it. As it has been quoted previously, the common octopus varies its behaviour among localities due to regional conditions. In this sense, it is important to understand how climate is affecting octopus in the Canaries since it is one of the fisheries target species. With this aim, we hypothesis how Sea Surface Temperature (SST) and the North Atlantic Oscillation (NAO) may be controlling the $O$. vulgaris in the Canary domain, through a seasonal scale approach; to elucidate if climate is the possible main cause of the observed seasonal fluctuations in this population.

\section{Materials and methods}

\subsection{Data set}

\subsubsection{Octopus fishery data}

The fishing data from 1989 to 2007 were obtained from the daily catch recorded by a single fishmonger who marketed the total catch obtained in the trap fishery landed in the Southwest of Gran Canaria 

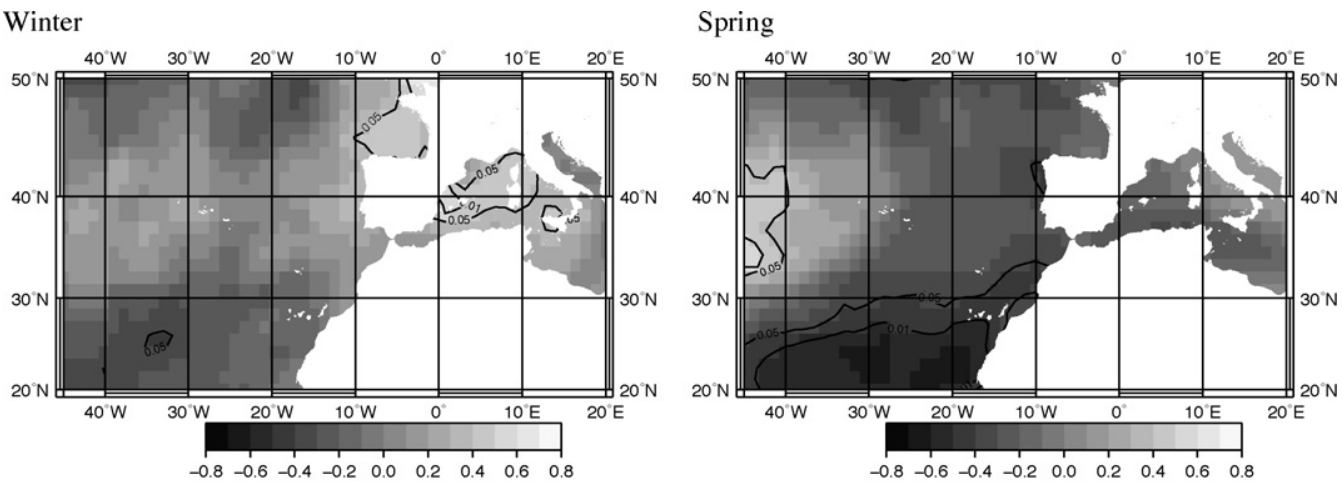

Summer

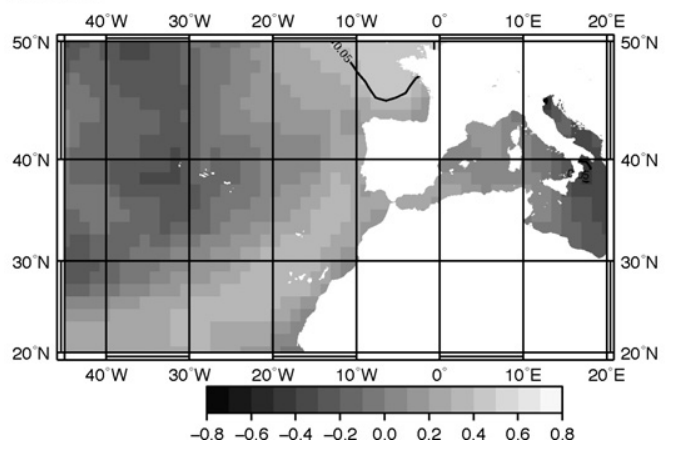

Autumn

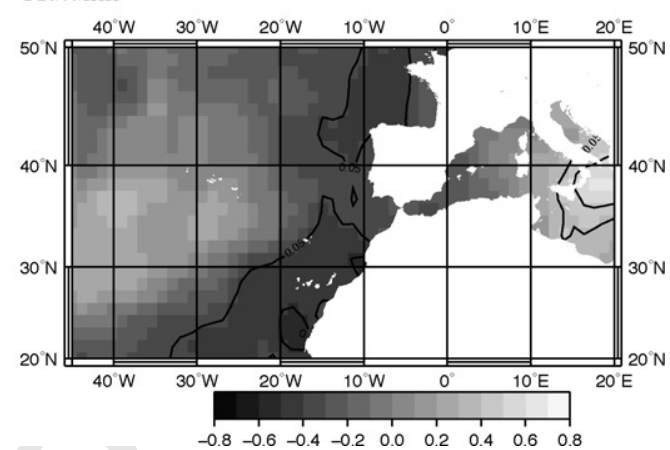

Fig. 2. Index of correlation between NAO index and SST at each point by seasons. The black line is the $p$-value at 0.01 ( $99 \%$ ) and 0.05 ( $95 \%$ ).

(Port of Mogán, Fig. 1), which is representative for all the islands, since it is one of the ports with the major fishery activity within the Archipelago, in fishing potential and in the number of catches landed (it represent over $25 \%$ of the total yearly captures of benthic and demersal fish landed in Gran Canaria, decreasing to the 10\% if mackerel and tuna captures are included; Gobierno de Canarias, unpublished data). In relation with this, for instance, $O$. vulgaris is the predominant species, after seabreams (Hernández-García et al., 1998), in the fisheries between January and June, because from May to February they focus on tuna (González et al., 1991). Variations in catches through seasons are due to the life cycle of the $O$. vulgaris, which present two peaks as described previously, but also to the fishing objectives at each time of the year (Hernández-García et al., 1998). However, fishmongers do not exclude species at any time, so the catches are a proxy index of abundance. When analysing the effort and catches independently (results not shown), it can be seen that the fishing effort has not changed through the years in a significant way. In contrast, the octopus catches reflect variability, different from the life cycle seasonality one. Due to this, it was considered that other factors, as climatic ones, might be playing a key 1 role in the evolution of this stock (Fig. 2).

The CPUE was estimated monthly from the total weight in kilograms of octopus caught per month divided by the monthly effort deployed. Afterward, seasonal means were calculated for all the years and trend removed for each new series to avoid the possible overfishing effect. We used, as an effort unit, the average number of days devoted to trap fishery per boat (sensus Hernández-García et al., 1998).

\subsubsection{North Atlantic Oscillation (NAO) data}

The NAO is a north-south dipole of anomalies, with one centre (low pressure system) located over Greenland and the other centre of opposite sign spanning the central latitudes of the North Atlantic between the Azores (Ponta Delgada) and Portugal (Lisbon) (high pressure system). This atmospheric predominant situation over the Atlantic, combining parts of the East and West Atlantic patterns as defined by Wallace and Gutzler (1981) for winter. It is noteworthy that the Canary Islands are in the southern limit of influence of this climatic pattern, so the impact of it on the island environment is almost undetectable (Ganzedo-López, 2005), but in certain periods it influence is strong enough (this work).

The NAO index data came from the NOAA database, while monthly mean standardized $500 \mathrm{mb}$ height anomalies were obtained from the CDAS, from 1950 to 2000.

\subsubsection{Sea Surface Temperature (SST) data}

Two kinds of SST data have been used for this study: (i) the Reynolds et al. (2002) SST from December 1982 to January 2007, to plot the maps of correlations and significations; (ii) the Kaplan et al. (1998) SST for local statistical analysis (South of Gran Canaria, $28.5^{\circ} \mathrm{N} / 16.5^{\circ} \mathrm{W}$ ), from January 1989 to December 2007.

\subsection{Statistical analysis}

\subsubsection{Exploratory CPUE data analysis}

A boxplot analysis and a cross-autocorrelation analysis were carried out using time data to explore the existence of seasonal components and to estimate autocorrelation (Fig. 3) in catches series. Statistical analysis of the series assumes stationarity. This implies that the series does not contain trends or cycles.

Monthly CPUE were averaged over seasons in order to obtain a time-series of CPUE per season of the year.

\subsubsection{Seasonal relations between NAO and SST}

To identify and to quantify the significance of the effect of the NAO index with respect to SST, Pearson's correlation maps with significance isolines $(95 \%(0.05)$ and $99 \%(0.01))$ were plotted, for points within the quadrant $20-50^{\circ} \mathrm{N}$ and $45^{\circ} \mathrm{W}$ to $20^{\circ} \mathrm{E}$, at a resolution of $1^{\circ} \times 1^{\circ}$. To that effect, (i) The trends have already been removed from the data set (NAO and SST data). (ii) The Pearson correlation was used between SST data (Reynolds et al., 2002) and NAO index, between 1982 and 2007. 

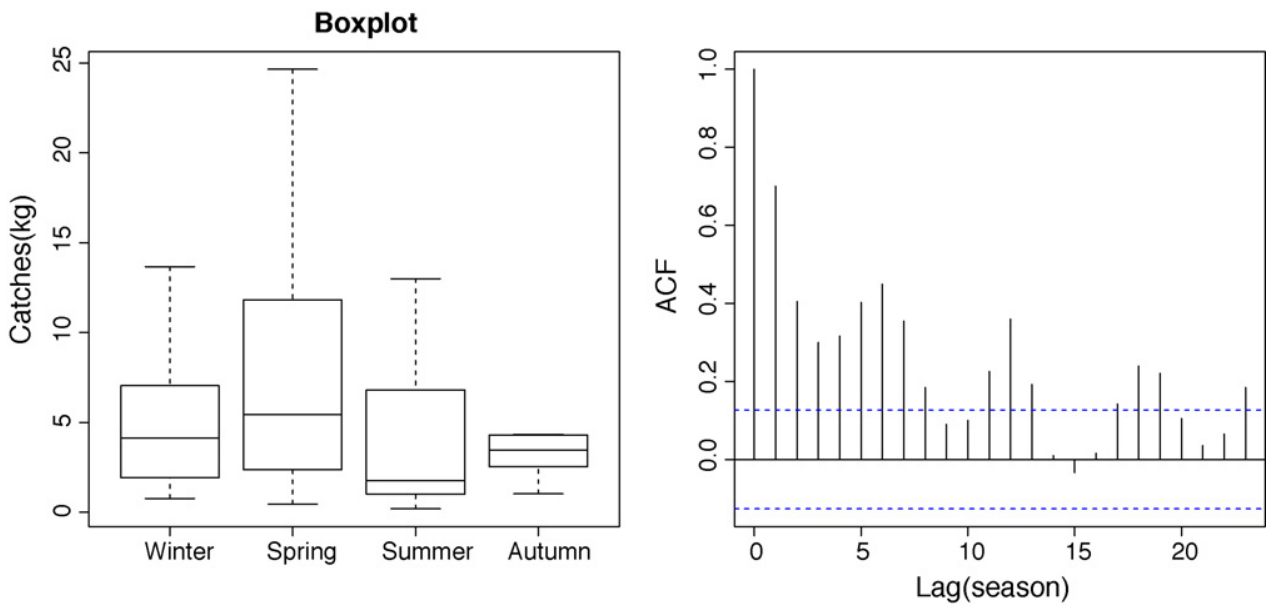

Fig. 3. Boxplot (left) and ACF of monthly CPUE (right).

\subsubsection{Statistical analyses between CPUE and environmental data}

The relationship between the NAO teleconnection pattern, SST and the statistics of CPUE was evaluated. A traditional analysis based on Pearson's correlation coefficient between CPUE, SST (Kaplan et al., 1998) and NAO index was performed. After removing data trend, correlation coefficient has been checked against the hypothesis that it was zero with a $95 \%$ confidence level. The reduction in the degrees of freedom due to the autocorrelation of the series has been considered in the test. In order to do so, a Monte
Carlo test has been used. Several realizations $(500,000)$ of autoregressive processes (AR $(1)$ ) with the corresponding autocorrelation for each of the tested series have been created, and the correlation coefficients of segments with the same length as the tested series have been used to create an experimental histogram, which represents the distribution of correlation coefficients from the AR (1) noise processes. Values of the correlation coefficient under (above) the $2.5 \%$ (97.5\%) percentiles in the experimental distribution of correlation coefficients obtained from the Monte Carlo analysis were
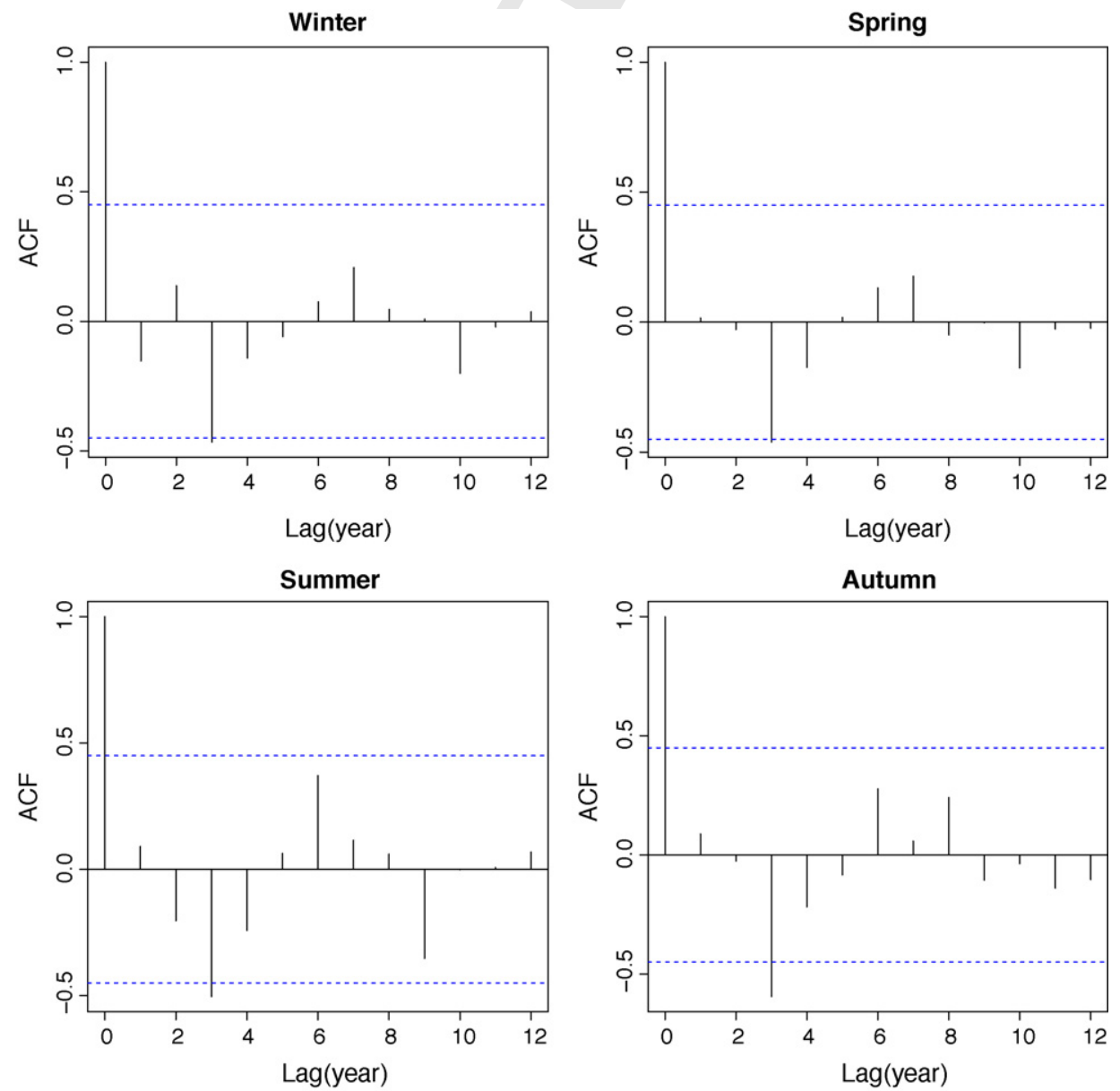

Fig. 4. ACF of seasonal CPUE. 
Table 1

Q4 Significant Pearson correlation pairs between CPUE and climatic variables.

\begin{tabular}{|c|c|c|c|c|}
\hline & $\mathrm{SST}_{\text {winter }}$ & $\mathrm{SST}_{\text {spring }}$ & $\mathrm{SST}_{\text {summer }}$ & $\mathrm{SST}_{\text {autumn }}$ \\
\hline $\mathrm{CPUE}_{\text {winter }}$ & $-0.64^{* *}$ & $-0.51^{*}$ & -0.34 & -0.38 \\
\hline CPUE $_{\text {spring }}$ & $\underline{\Lambda}_{0.66^{* *}}$ & -0.4 & -0.33 & -0.41 \\
\hline $\mathrm{CPUE}_{\text {summer }}$ & $-0.60^{* *}$ & -0.41 & -0.34 & $-0.58^{* *}$ \\
\hline \multirow[t]{2}{*}{ CPUE $_{\text {autumn }}$} & -0.25 & -0.44 & -0.45 & $-0.61^{* *}$ \\
\hline & $\mathrm{NAO}_{\text {winter }}$ & $\mathrm{NAO}_{\text {spring }}$ & $\mathrm{NAO}_{\text {summer }}$ & $\mathrm{NAO}_{\text {autumn }}$ \\
\hline CPUE $_{\text {winter }}$ & -0.11 & $0.68^{* *}$ & -0.15 & 0.37 \\
\hline $\mathrm{CPUE}_{\text {spring }}$ & $\wedge_{0.07}$ & $0.57^{*}$ & -0.18 & $0.46^{*}$ \\
\hline CPUE $_{\text {summer }}$ & -0.01 & ภ.39 & -0.37 & $0.61^{* *}$ \\
\hline CPUE & $\hat{\Lambda}_{0.08}$ & 0.12 & $-0.49^{*}$ & $0.59^{* *}$ \\
\hline
\end{tabular}

considered significant. To facilitate the visualization, a matrix of scatterplots was produced.

When looking for the relationship between captures $\left(y_{i}\right)$ and climate descriptors $\left(x_{i}\right)$, a simple linear regression model $(\mathrm{lm})$ was used for describing paired data sets that are related in a linear manner (where $x$ is the independent variable and $y$ the dependent one). In the simple linear regression model, for describing the relationship between $x_{i}$ and $y_{i}$, an error term is added to the linear relationship as $y_{i}=\beta_{0}+\beta_{1} x_{i}+\varepsilon_{i}$. The value $\varepsilon_{i}$ is the error term
Table 2

Explained deviance of the CPUE series (in spring and in autumn), using $1 m$ model Q5 signif. codes: $\left.0,{ }^{\prime * * *}, 0.001,{ }^{\prime * * *} 0.01,{ }^{\prime * \prime} 0.05,^{\left(\cdot()^{\prime}\right.} 0.1, " 1\right)$.

\begin{tabular}{|c|c|c|c|}
\hline & Selected term & $p$-Value & Adjusted $R$-squared (\%) \\
\hline \multirow{2}{*}{\multicolumn{4}{|c|}{$\Lambda_{\text {SST }}^{\text {Climatic term in spring }}$}} \\
\hline & & & \\
\hline NAO & $\mathrm{NAO}^{(\cdot)}$ & 0.04 & 24.5 \\
\hline SST & $\mathrm{SST}^{(.)}$ & 0.09 & 11.12 \\
\hline NAO & $\mathrm{NAO}^{*}$ & 0.01 & 28.64 \\
\hline \multicolumn{4}{|c|}{ Climatic term in autumn } \\
\hline SST & $\mathrm{SST}^{(\cdot)}$ & & \\
\hline NAO & $\mathrm{NAO}(\cdot)$ & 0.004522 & 42.71 \\
\hline SST & $\mathrm{SST}^{\mathrm{N}}$ & 0.005040 & 34.21 \\
\hline NAO & $\mathrm{NAO}^{* *}$ & 0.007672 & 31.13 \\
\hline
\end{tabular}

(residual term), and the coefficients $\beta_{0}$ and $\beta_{1}$ are the regression coefficients. The data vector $x$ is called the predictor variable and $y$ the response variable. The coefficient of determination $\left(R^{2}\right)$ is defined as the decomposition of the total sum of squares into the residual sum of squares and the regression sum of squares: $R^{2}=$ $1-\left(\sum\left(y_{i}-\hat{y}_{i}^{2}\right) / \sum\left(y_{i}-\bar{Y}_{2}^{i}\right)=\sum\left(\hat{y}_{i}-\bar{Y}_{2}^{i}\right) / \sum\left(y_{i}-\bar{Y}_{2}^{i}\right)\right)$. Here, $\hat{y}_{i}$ is the predicted term of $y_{i}$, which is the original value of the captures, and $\bar{Y}_{i}$ is the mean. The $R^{2}$ is interpreted as the proportion of the
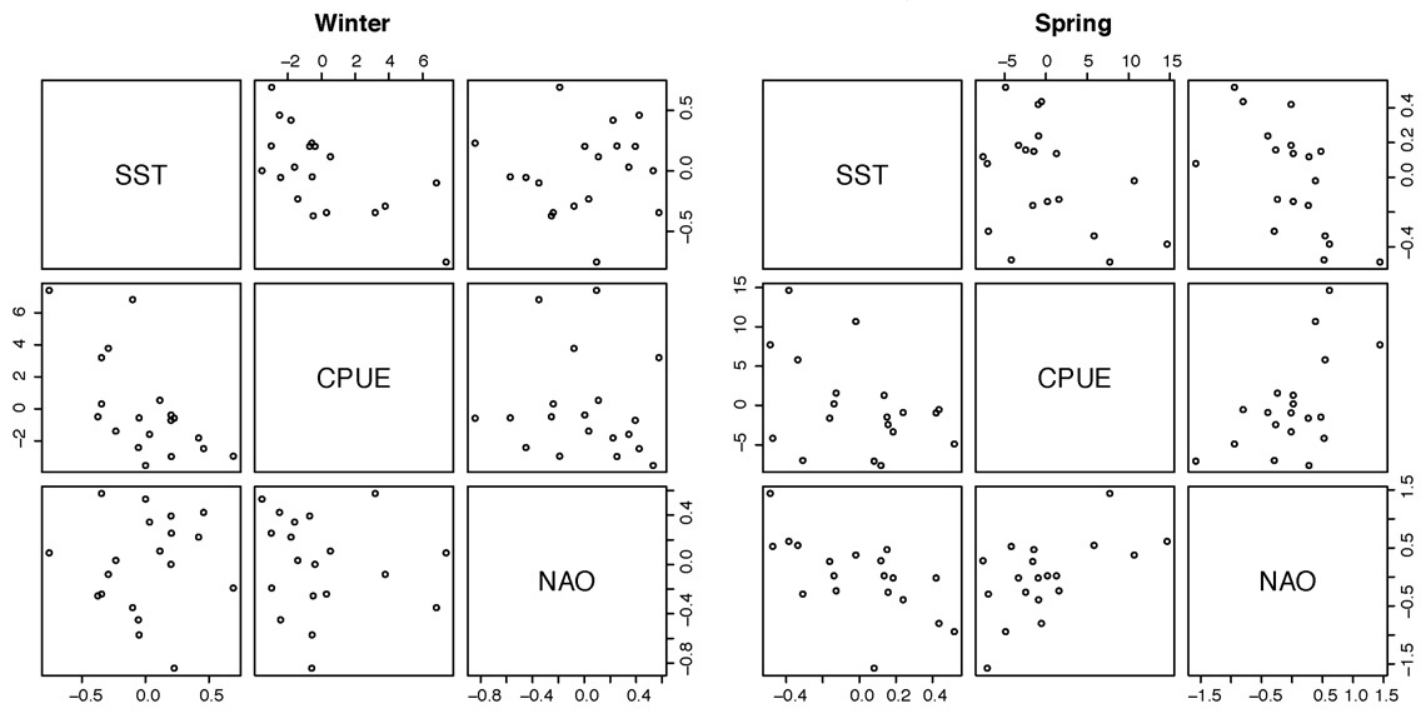

\section{Summer}
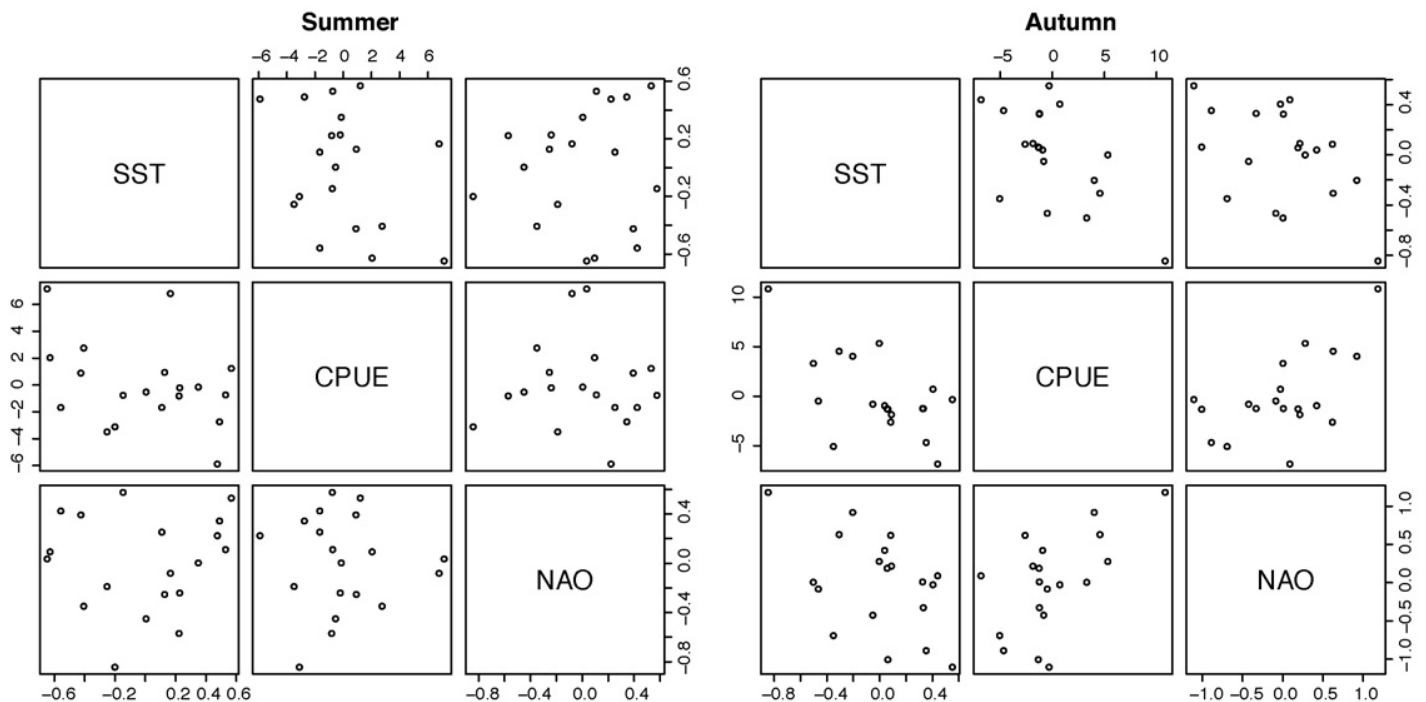

Fig. 5. Matrix of scatterplots of SST, NAO and CPUE for seasonal differences. 
total response variation explained by the regression. The $100 \%$ of the variation is explained by the regression line. The adjusted $R^{2}$ divides the sums of squares by their degrees of freedom (Wilks, 2006).

The capture was considered as the response (output or $y$ ) variable in the analysis, to facilitate the analyses and visual comparison of general trends. We used the following explanatory variables $(x)$ in the Im model: (a) SST (Kaplan et al., 1998) and (b) NAO index. With this, to evaluate the possible colinearity among climatic terms and to elucidate if the explained variance is increased when they are considered together or independently, three types of lm's were carried out: (i) combining the influence of the NAO and SST; (ii) analysing the effect of the SST solely and, finally (iii) the influence of the NAO on captures.

We really wanted to be sure about the constancy (in the time) of variance and normality of the residuals. To that effect: (i) The Shapiro-Wilk test (Shapiro and Wilk, 1965) was used for testing that the residuals are normally distributed ( $p$-value $>\alpha=0.05$, confirmed the null hypothesis: normality). (ii) The Durbin-Watson function (Durbin and Watson, 1950, 1951) was used for testing whether there is autocorrelation in the residual from $\mathrm{lm}$.

\section{Results}

The Boxplot (Fig. 3, left) shows that $20.87 \%, 35.82 \%, 17.78 \%$ and $25.52 \%$ of the total CPUE are caught in winter, spring, summer and autumn, respectively. The auto correlation function (ACF) shows autocorrelation in the series (Fig. 3, right). Consequently, to avoid the inter-annual seasonality, seasonal averages of the CPUE were calculated. Thereafter, seasonal series were analysed in an independent way. Fig. 4 shows the ACF of these seasonal series. This was done with the only aim of verifying our models.

When the NAO index was correlated against the SST data grid, the relationship obtained was high and significant in spring and autumn around the Canary Islands. Significant correlations were found for SST in the local point $\left(28.5^{\circ} \mathrm{N} / 16.5^{\circ} \mathrm{W}\right)$ in spring $(r=-0.47$, $p<0.05)$ and autumn $(r=-0.48, p<0.05)$. While no significant correlations were obtained for winter $(r=-0.16, p>0.05)$ and summer $(r=0.36, p>0.05)$. Table 1 (up) and fig. 5 show the correlations obtained between the seasonal CPUEs and the SST. It is worth emphasising that all pairs were negatively correlated. That is, when the CPUE increases, the SST decreases. Table 1 (down) shows the correlations obtained between the seasonal CPUEs and the NAO index, and both variables evolve simultaneously in spring and autumn. While in winter and summer they have an inverse behaviour almost always.

Table 2 shows the stepwise procedure of the three lineal models for these climate variables in spring (up) and autumn (down). Three types of models have been carried out: (i) SST and NAO combined effect and (ii) SST and (iii) NAO effect independently. In spring, the NAO is the variable that is playing a key role on octopus population when considering both variables together since there is no colinearity and the NAO is responsible for the highest explained variance ( $24.5 \%$ in model (i) and $28.65 \%$ when considering it solely); the SST by itself, only support the $11.12 \%$ of the explained variance. While in autumn there seems to be an influence of both climatic terms ( $42.71 \%$ in the combined model). This means that there is colinearity among them. Looking after the \% of explained variance of each parameter individually, the SST (34.21\%) and the NAO (31.13\%) explains the octopus fluctuations in roughly the same proportion, although the temperature seems to be the more important one.

Table 3 shows the results of checking the $\mathrm{lm}$ model through Shapiro-Wilk (normality, Shapiro and Wilk, 1965) and Durbin-Watson analyses (autocorrelation, Durbin and Watson, 1950,1951 ) for spring and autumn. It can be seen that both seasons have a normal behaviour (Shapiro-Wilk); meanwhile, when
Table 3

Linear model checking. Shapiro-Wilk and Durbin-Watson test.

\begin{tabular}{|c|c|c|c|c|c|}
\hline & \multicolumn{2}{|c|}{ Shapiro-Wilk test } & \multicolumn{3}{|l|}{ Durbin-Watson } \\
\hline & $w$ & $p$-Value & Autocorrelation & D-W statistic & $p$-Value \\
\hline \multicolumn{6}{|c|}{ Climatic terms in spring } \\
\hline $\begin{array}{l}\text { SST } \\
\text { NAO }\end{array}$ & 0.96 & 0.51 & 0.21 & 1.40 & 0.19 \\
\hline 今st & 0.95 & 0.39 & -0.15 & 2.22 & 0.60 \\
\hline NAO & 0.96 & 0.99 & 0.25 & 1.31 & 0.12 \\
\hline \multicolumn{6}{|c|}{ Climatic terms in autumn } \\
\hline $\begin{array}{l}\text { SST } \\
\text { NAO }\end{array}$ & 0.99 & 0.99 & -0.42 & 2.83 & 0.07 \\
\hline SST & 0.97 & 0.76 & -0.20 & 2.38 & 0.44 \\
\hline NAO & 0.99 & 0.99 & -0.35 & 2.67 & 0.11 \\
\hline
\end{tabular}

looking for autocorrelation through the Durbin-Watson test, it can be appreciated that there is no evidence of serials correlations in those residuals $(p>0.05)$ for spring or autumn.

\section{Discussion}

The biology, ecology and fishery of common octopus off the Northwest Africa have been well described from a global point of view (Nigmatullin and Ostapenko, 1977; Hatanaka, 1979; Pereiro and Bravo de Laguna, 1979; Nigmatullin and Barkovsky, 1990; Balguerías et al., 2000, 2002). However, a great number of questions still remain unanswered. Among them, the role of climatic variability in the fluctuations of octopus abundance on intra-annual and decadal time scales (Hernández-García et al., 1998).

In this context, our results show that there is an environmental variability effect on $O$. vulgaris abundance off the Canary Islands, and that, at a seasonal scale, it can be summarised by the SST variability through the year. Correlations between fishery yield and temperature in different seasons must be the consequence of the effect of this latter factor on octopus paralarvae survival, growth rates, age of juvenile benthic settlement and timing of the reproductive peaks; that is, on recruitment to the fishery. In relation to this, Hernández-García et al. (2002) described the existence of two annual cohorts in the common octopus population off the Canary Islands. These two cohorts are the result of two annual reproductive peaks, the first one during April and the second between October and November, coinciding with the NAO changes from lower to higher values and vice versa. Moreover, the relationship between the SST and the NAO index has already been established in several studies (Cayan, 1992; Visbeck et al., 1998; Seager et al., 2000; Marshall et al., 2001; among others), although this relationship could be different on more local scales in yearly analyses (Visbeck et al., 2003; Pierce et al., 2008). In this way, in spring and autumn, an inverse relationship between SST and NAO in the Canary domain was observed. Contrary, a direct one was detected in summer. This must be highlighted because when the NAO is treated from a seasonal point of view, always the winter is the predominant period, but not at the Canary Islands, where the NAO is an important atmospheric pattern mainly in spring and autumn. This is reflected in the SST, but also in the octopus abundance due to its seasonal reproductive pattern described above. So, the highly negative correlations between SST and NAO coincide with peaks in octopus catches.

Nevertheless, the SST-NAO influence probably goes further than its effect on reproductive aggregations and availability of adults to the fishery. The paralarvae survival, recruitment and abundance are under the influence of many factors other than temperature and food (Van-Heukelen, 1979; Villanueva, 1995), which acquire more or less relevance depending on the geographical scale and local features (Mangold, 1983; Hernández-García and Castro, 1998; Faure et al., 2000; Semmens et al., 2007; Otero et al., 2008). Clearly, octo- 
pus biomass and its accessibility to fishery are the consequence of a heterogeneous collection of environmental variables, together with important local components that modulate their recruitment success, distribution patterns, abundance and behaviour of this cephalopod species (Hanlon and Messenger, 1998; Faraj and Bez, 2007). At the Canaries, the octopus present mating and spawning stages the year-round, although with the spring and autumn peaks described before, but both peaks fluctuate in time from year to year (Hernández-García et al., 2002). The fluctuations observed may be due to a combination of the fishing strategy and the octopus life cycle. For instance, Hernández-García et al. (1998) observed that adults octopus concentrate in shallower water for spawning, being more accessible to the fishery, and during the summer, the population move downward in the water column, decreasing their abundance in the fishing grounds. Even though, for seasonal fluctuations, the life cycle is the predominant influencing factor upon fishing strategies, it is necessary to consider that large-scale teleconnection patterns (i.e. NAO) might also influence those biological patterns (Semmens et al., 2007), and the fishery strategies in many different ways (i.e. sea conditions). Nonetheless, as pointed out by Hernández-García et al. (2002), the direct and indirect influences of the NAO on the octopus fishery should be also emphasised. It should be noted that the temperature registered is a consequence of coupling between the atmosphere (the NAO as an atmospheric phenomenon) and the ocean.

As expected, the NAO leads the climatic and biological cycles in the Central-east Atlantic Ocean. Clearly, all its atmospheric states have different degrees of influence on the ocean and, indirectly, on marine resource populations (i.e. Visbeck et al., 2003). Previous studies (Kronvnin, 1995; Santiago, 1998; Corten, 2001; Mysterud et al., 2003; among others) have highlighted that the NAO is reflected in the fluctuations of the fisheries, but it is also known that south off the Canary region it is less accurate in describing biological and climatic phenomena (García-Herrera et al., 2001). Overall, this paper emphasises the importance of the NAO index both directly and through the SST, as a controlling factor of common octopus abundance in the Canary Archipelago in a seasonal scale (spring and autumn). Through the lineal model, it can be concluded that in spring is the NAO the main controlling climate factor, with a significant explained variance of $28.64 \%$ (the SST explains the $11.12 \%$, but no significant). During autumn the effect of the SST and the NAO is not such difference: $31.13 \%$ of the explained variance through the NAO and a $34.21 \%$ explained by the SST.

It has also been demonstrated why more local climatic indices should be built to reach a better understanding of the interaction between climate variations and exploited marine organisms, because their sensitivity, particularly cephalopods, to environmental fluctuations is an important factor in stock assessment and management. In addition, octopus catch fluctuations may be indicators of environmental changes.

\section{Uncited reference}

\section{$\Lambda^{\mathrm{NOAA}(2009) \text {. }}$}

\section{Acknowledgements}

Authors would like to sincerely thank Dr. Jon Sáenz (University of the Basque Country) for inestimable help with the data analyses. In addition, all our gratitude goes also to the Mogán fishery association and a special mention to Leo Hernández, for her good will and for giving us the octopus catch and effort data. We also want to thank Lorena Couce for her help. A.M. Caballero-Alfonso has a scholarship from the Spanish Ministry of Science and Innovation (MICINN), and this work has been also supported by the MICINN
National Research Programme (AGL2006-10448/ACU). The EKLIMAXXI project (Basque Government, Department of Industry and Basque Meteorological Service-Euskalmet, Project ETORTEK07/01IE07-190) is acknowledged for funding the position of U. Ganzedo.

\section{References}

Balguerías, E., Quintero, M.E., Hernández-González, C.L., 2000. The origin of the Saharan Bank cephalopod fishery. ICES J. Mar. Sci. 57, 15-23.

Balguerías, E., Hernández-González, C., Perales-Raya, C., 2002. On the identity of Octopus vulgaris Cuvier, 1797 stocks in the Saharan Bank (Northwest Africa) and their spatio-temporal variations in abundance in relation to some environmental factors. Bull. Mar. Sci. 71 (1), 147-163.

Bjerknes, J., 1964. Atlantic air-sea interactions. Adv. Geophys. 10, 1-82.

Cayan, D.R., 1992. Latent and $\mathrm{sensible} \mathrm{heat} \mathrm{flux} \mathrm{anon} 1$ lies over the northern oceans: driving the sea surface temperature. J. Phys. Oceanogr. 22, 859-881.

Corten, A.d., 2001. Herring and climate. Changes in the distribution of the North Sea her个ng due to climate flư⿱ 228 pp.

Durbin, J., Watson, G.S., 1950. Testing for serial correlation in Least Square Regression I. Biometrika 37, 409-428.

Durbin, J., Watson, G.S., 1951. Testing for serial correlation in Least Square Regression II. Biometrika 38, 159-179.

Faraj, A., Bez, N., 2007. Spatial considerations for the Dakhla stock of Octopus vulgaris: indicators, patterns, and fisheries interactions. ICES J. Mar. Sci. 64, $1820-1828$

Faure, V., Abdellahi Inejih, C., Demarcq, H., Cury, P., 2000. The importance of retention processes in upwelling areas for recruitment of Octopus vulgaris: the example of the Arguin Bank (Mauritania). Fish. Oceanogr. 9 (4), 343-355.

Ganzedo-López, U., 2005. Eventos climáticos a pequeña escala y la pesca del atún blanco (Thurnus alalunga) en las Islas Canarias. Ph.D. Thesis. Univ. Las Palmas de Gran Canaria. Spain.

García-Herrera, R., Gallego-Puyol, D., Hernández-Martín, E., Gimeno-Presa, L. Ribera-Rodríguez, P., 2001. Influence of the North Atlantic Oscillation on the Canary Islands precipitation. J. Climate 14, 3889-3903.

González, J.A., SanAdna, J.I., Carrillo, J., 1991. La pesca en el Puerto de Mogán (Islas Canar(as): flota, artes y análisis de las capturas entre 1980 y 1990. In: Cabildo Insular de Gran Canaria (Ed.), Informe Técnico del Centro de TeĈología Pesquera (Pesquerías). Telde, Las Palmas, 32 pp.

Guerra, A., 1992. Mollusca cephalopoda. In: Fauna Ibérica, Vol. 1, Museo Nacional de Ciencias Naturales. Consejo Superior đe Investigaciones Científicas, Madrid, 327 pp.

Hanlon, R.T., Messenger, J.B., 1998. Cephalopod Behaviour. Cambridge University Press, $248 \mathrm{pp}$

Hatanaka, H., 1979. Studies on the fisheries biology of common octopus off northwest coast of Africa. Bull. Far Seas Fish. Kes. Lab. 17, 13-124.

Hernández-García, V., Castro, J.J., 1998. Morphological variability in Illex coindetii (Cephalopoda: Ommastrephidae) along the North-west coast of Africa. J. Mar. Biol. Assoc. U.K. 78, 1259-1268.

Hernández-García, V., Hernández-López, J.L., Castro, J.J., 1998. The octopus (Octopus vulgaris) in the small-scale trap fishery off the Canary Islands (Central-East Atlantic). Fish. Res. 35, 183-189.

Hernández-García, V., Hernández-López, J.L., Castro-Hernández, J.J., 2002. On the reproduction of Octopus vulgaris off the coast of the Canary Islands. Fish. Res. 57, 197-203.

Hernández-López, J.L., Castro-Hernández, J.J., Hernández-García, V., 2001. Age determined from the daily deposition of concentric rings on common octopus (Octopus vulgaris) beaks. Fish. Bull. 99, 679-684.

Hsieh, Ch-h., Ohman, M.D., 2006. Biological responses to environmental forcing: the linear tracking window hypothesis. Ecology 87 (8), 1932-1938.

Kaplan, A., Cane, M., Kushnir, Y., Clement, A., Blumenthal, M., Rajagopalan, 1998

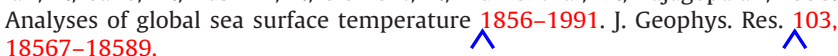

Katsanevakis, S., Verriopoulos, G., 2006a. Seasonal population dynamics of Octopus vulgaris in the eastern Mediterranean. ICES J. Mar. Sci. 63, 151-160.

Katsanevakis, S., Verriopoulos, G., 2006b. Modelling the effect of temperature on hatching and settlement patterns of meroplanktonic organisms: the case of the octopus. Sci. Mar. 70 (4), 699-708.

Kronvnin, A.S., 1995. A comparative study of climatic changes in the North Pacific and North Atlantic and their relation to the abundance of fish stocks. Beamish R.J. (Ed.), Climate Change and Northern Fish Populations. Can. Spec. Publ. Fish. Aquat. Sci. 121, 181-198.

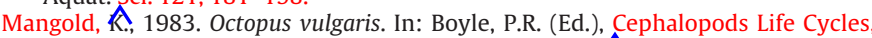
Vol. I: Species Accounts. Academic Press, London, pp. $355-364$.

Marshall, J.H., Johnson, H., Goodman, J., 2001. A study of the in Yaction of the North Atlantic Oscillation with the ocean circulation. J. Climate 14, 1399-1421.

Moreno, A., Pereira, J., Arvanitidis, C., Robin, J.P., Koutsoubas, D., Perales-Raya, C. Cunha, M.M., Balguerías, E., Denis, V., 2002. Biological variations of Logilo vulgaris (Cephalopoda: Loliginidae) in the eastern Atlantic and Mediterranean. Bull. Mar. Sci. 71 (1), 515-534.

Mysterud, A., Stenseth, N.C., Yoccoz, N.G., Ottersen, G., Langvatn, R., 2003. Response of terrestrial ecosystems to climate variability associated with the North Atlantic Oscillation. In: Hurell, J., Kushnir, Y., Ottersen, G., Visbeck, M. (Eds.), The North Atlantic Oscillation (NAO). NGU Monogs, pp. 235-262. 
Nigmatullin, Ch.M., Barkovsky, A.E., 1990. Seasonal grouping of Octopus vulgaris off Cap Blanc (Mauritania). In: 5th All-Union Conference on the Comm. Invertebrates, October 9-13, 1990, Minsk (Naroch). VNIRO, Moscow, pp. 87-89 (thesis report领

Nigmatullin, Ch.M., Ostapenko, A.A., 1977. Several features of the ecology of the common octopus (Octopus vulgaris) off the coast of Northwest Africa. In: All USSR Science Conference on Util. Comm. Invertebrates, pp. 56-57 (abstr. report).

NOAA. Earth System Research Laboratory. Physical Science Division. http://www.cdc.noaa.gov/cdc/data.noaa.oisst.v2.html (assessed 06.05.2009).

Otero, J., Álvarez-Salgado, X.A., González, A.F., Miranda, A., Głoom, S.B., Cabanas, J.M., Casas, G., Wheatley, B., Guerra, A., 2008. Bottom-up control of common octopus Octopus vulgaris in the Galician upwelling system, northeast Atlantic Ocean. Mar. Ecol. Prog. Ser. 362, 181-192.

Pereiro, J.A., Bravo de Laguna, J., 1979. Dinámica de la población y evaluación de los recursos del pulpo en el Atlántico Centro Oriental. Bol. Inst. Esp. Oceanog. 5, 69-105.

Pierce, G.H., Valavanis, V.D., Guerra, A., Jereb, P., Orsi-Relini, L., Bellido, J.M., Katara, I., Piatkowski, U., Pereira, J., Balguerias, E., Sobrino, I., Lefkaditou, E., Wang, J., Santurtun, M., Boyle, P.R., Hastie, L.C., MacLeod, C.D., Smith, J.M., Viana, M., González, A.F., Zuur, A.F., 2008. A review of cephalopod-environment interactions in European seas. Hydrobiologia 612, 49-70.

Reynoldऽ, R.W., Rayner, N.A., Smith, T.M., Stokes, D.C., Wang, W., 2002. An improved in situ and satellite, SST analysis for climate. J. Climate 15, 1609-1625.

Santiago, J., 1998. North Atlantic Oscillation and recruitment of temperature tunas. ICCAT collection. Vol. Sci. Pap. XLVIII (3), 240-249.

Seager, R., Kushnir, Y., Visbeck, M., Naik, N., Miller, J., Krahmann, G., Cullen, H., 2000. Causes of the Atlantic Ocean climate variability between 1958 and 1998 . J. Climate 13, 2845-2862.

Semmens, J.M., Pecl, G.T., Gillanders, B.M., Waluda, C.M., Shea, E.K., Jouffre, D., Ichii, T., Zumholz, K., Katugin, O.N., Leporati, S.C., Shaw, P.W., 2007. Approaches to resolving cephalopod movement and migration patterns. Rev. Fish Biol. Fish. $17,401-423$.
Shapiro, S.S., Wilk, M.B., 1965. An analysis for variance test in normality (complete samples). Biometrika 52 (3/4), 591-611.

Sims, D.W., Genner, M.J., Southward, A.J., Hawkins, S.J., 2001. Timing of squid migration reflects North Atlantic climate variability. Proc. R. Soc. Lond. B 268 2607-2611.

Sobrino, I., Silva, L., Bellido, J.M., Ramos, F., 2002. Rain, river discharges and sea temperature as factors affecting to abundance of two coastal benthic cephalopod species in the Gulf of Cádiz (SW of Spain). Bull. Mar. Sci. 71 (2) 851-865.

Solari, A.P., 2008. New non-linear model for the study and exploitation of the Nishery resources. Ph.D. Thesis. Universidad de Las Palmas de Gran CanÂia, Spain, 298 pp. http://vpn1.ulpgc.es/http/0/contentdm.ulpgc.es/cdm4/ Atem_viewer.php?CISOROOT=/POSTULPGC\&CISOPTR=3190\&CISOBOX=1\&REC=3.

Van-Heukelen, W.F. 1979. Environmental control of reproduction and life span in octopus: an hypothesis. In: Stancyk, S.E. (Ed.), Reproductive Ecology of Marine Invertebrates, The Belle W. Baruch Library in Marine Science, vol. 9. Univ. South
Carolina Press, Columbia, SC, pp. 123-133.

Villanueva, R., 1995. Experimental rearing and growth of planktonic Octopus vulgaris from hatching to settlement. Can. J. Fish. Aquat. Sci. 52, 2639-2650.

Visbeck, M., Cullen, H., Krahmann, G., Naik, N., 1998. An oceans model's response to North Atlantic Oscillation like wind forcing. Geophys. Res. Lett. 25, 4521-4524.

Visbeck, M., Chassignet, E.P., Curry, R.G., Delworth, T.L., Dickson, R.R., Krahmann, G., 2003. The ocean's response to North Atlantic Oscillation variability. In: Hurrel, J.W., Kushnir, Y., Ottersen, G., Visbeck, M. (Eds.), The Norł Atlantic Oscillation. Climatic Significance and Environmental Impact.American Geophysical Union Books Board, USA, 279 pp.

Wallace, J.M., Gutzler, D.S., 1981. Teleconnections in the geopotential height field during the northern hemisphere winter. Mon. Weather Rev. 109, 784-812.

Wilks, D.S., 2006. Statistical Methods in Atmospheric Sciences, second edition. Academic Press, AmsterdarîBoston, 627 pp. 